\title{
Health-related quality of life and mental health problems after a disaster: Are chronically ill survivors more vulnerable to health problems?
}

\author{
Bellis van den Berg ${ }^{1,2}$, Peter G. van der Velden ${ }^{3}$, C. Joris Yzermans $^{4}$, Rebecca K. Stellato ${ }^{1}$ \& Linda \\ Grievink $^{1}$ \\ ${ }^{1}$ National Institute for Public Health and the Environment (RIVM), 3720 BA, Bilthoven, The Netherlands; \\ (E-mail: bellis.van.den.berg@rivm.nl); ${ }^{2}$ Institute of Risk Assessment Sciences (IRAS)Utrecht University, \\ Utrecht, the Netherlands; ${ }^{3}$ Institute for Psychotrauma (IvP), Zaltbommel, the Netherlands; ${ }^{4}$ Netherlands \\ Institute for Health Services Research (NIVEL), Utrecht, the Netherlands
}

Accepted in revised form 9 June 2006

\begin{abstract}
Studies have shown that the chronically ill are at higher risk for reduced health-related quality of life (HRQL) and for mental health problems. A combination with traumatic events might increase this risk. This longitudinal study among 1216 survivors of a disaster examines whether chronically ill survivors had a different course of HRQL and mental health problems compared to survivors without chronic diseases. HRQL and mental health problems were measured 3 weeks, 18 months and 4 years post-disaster. Data on pre-disaster chronic diseases was obtained from the electronic medical records of general practitioners. Random coefficient analyses showed significant interaction effects for social functioning, bodily pain and emotional role limitations at T2 only. Chronically ill survivors did not consistently have a different course of general health, physical role limitations, and mental health problems. In conclusion, chronic diseases were not an important risk factor for impaired HRQL and mental health problems among survivors.
\end{abstract}

Key words: Chronic diseases, Disasters, Longitudinal studies, Mental health, Quality of life, Risk factors

Abbreviations: CI - confidence interval; EMR - electronic medical record; GP - general practitioner; HRQL - health-related quality of life; IES - impact of event scale; PTSD - post-traumatic stress disorder; RAND-36 - Questionnaire on general health (36 items); RCA - random coefficient analysis; SCL-90 Symptom Checklist (90 items); SD - standard deviation

\section{Introduction}

Studies have shown that chronically ill patients have reduced health-related quality of life (HRQL) and are relatively more at risk for mental health problems than those without a chronic disease [1-6]. The combination of a distressing chronic disease with other stressful life events might increase this risk. For example, studies have shown that social, financial, work-related and relationship problems increase the probability of mental problems and functional impairment among the chronically ill $[4,7]$.

Disasters and other collective traumatic events such as terrorist attacks are extremely stressful for most people. Studies following these types of events have shown reduced levels of HRQL and elevated prevalence rates of post-traumatic stress disorder (PTSD), depression and anxiety [8-11]. The question arises whether chronically ill survivors are at higher risk for increased levels of post-disaster functional impairment and mental 
health problems than survivors without chronic diseases.

The present study focuses on survivors who were involved in a major explosion of a fireworks depot that was situated in a residential area in the city of Enschede in the Netherlands (13 May, 2000). The explosion resulted in 23 deaths, over 900 people were injured and about 1200 people were forced to relocate because their houses were destroyed. Based on general population studies, we assumed that functional impairment and mental health problems were already common among the chronically ill prior to the disaster. To test the hypothesis that the experience of the disaster increases the risk for post-disaster health problems among chronically ill survivors, we examined whether they had a different course of HRQL and mental health problems compared to survivors without pre-disaster chronic diseases.

\section{Methods}

\section{Study design and participants}

After the fireworks disaster, a longitudinal survey studying the health consequences of the disaster was started. The first wave of this survey was performed between 2.5 and 3.5 weeks post-disaster (T1). All adult residents (i.e. survivors) were invited to participate. In total, 1567 survivors completed a questionnaire. Approximately 18 months postdisaster, from November 2001 to January 2002, the second wave (T2) was performed. In total, 1116 survivors (response $72 \%$ ) completed a questionnaire at T2. Nearly 4 years post-disaster, (JanuaryMarch 2004) a third survey was performed (T3); 995 survivors (response 66\%) completed a questionnaire. Details of the study population, nonresponse and procedures of the three waves have been described elsewhere [12-16].

After the fireworks disaster, all general practitioners (GP) in the affected city (Enschede) were invited to participate in a surveillance program. In the Dutch health care system, citizens are required to be registered at one general practice, and the GP serves as the gatekeeper to secondary care. In total, 44 out of 60 GPs $(73 \%)$ agreed to participate in the study [10]. The final study population consisted of 1216 survivors who participated at least at $\mathrm{T} 1$ of the health survey and who were registered in one of the participating general practices 1.5 years prior to the disaster.

\section{Measures}

Data on pre-disaster chronic diseases was obtained from the electronic medical records (EMR) of the GPs, and were registered according to the International Classification of Primary Care [17]. Survivors were defined as having a pre-disaster chronic disease if one or more chronic diseases from a cluster that has often been used in studies in the Dutch population [18], were registered in their EMR in the 1.5 years before the disaster (Table 1). Since only small numbers of survivors were diagnosed with the various chronic diseases, we could not distinguish between the different diseases.

The health survey included questions on demographic and lifestyle characteristics. HRQL was measured by the validated Dutch version of the RAND-36 [19]. Five of the nine subscales were

Table 1. Demographic characteristics of survivors with and without one or more pre-disaster chronic diseases ${ }^{\mathrm{ab}}$

\begin{tabular}{lcc}
\hline & $\begin{array}{c}\geq 1 \text { Pre-disaster } \\
\text { chronic disease }\end{array}$ & $\begin{array}{l}\text { No pre-disaster } \\
\text { chronic disease \% }\end{array}$ \\
\hline $\mathrm{N}(\%)$ & $427(35.1)$ & $789(64.9)$ \\
Male & 41.9 & $48.1^{*}$ \\
Age & & \\
$\quad 18-24$ & 4.7 & $13.6^{* *}$ \\
$25-44$ & 31.7 & 53.8 \\
$\quad 45-64$ & 43.7 & 27.7 \\
$\quad 65+$ & 20.0 & 5.0 \\
Married & 74.5 & $69.6^{*}$ \\
Education & & \\
$\quad$ Basic & 28.8 & $16.8^{* *}$ \\
$\quad$ Low & 34.1 & 31.4 \\
$\quad$ Middle & 26.1 & 32.6 \\
$\quad$ High & 11.0 & 19.2 \\
Immigrant & 28.6 & 29.4 \\
Currently smoking & 30.7 & $44.6^{* *}$ \\
cigarettes & & \\
\hline
\end{tabular}

${ }^{a}$ All survey data in this table were obtained at $\mathrm{T} 1$ of the study. ${ }^{\mathrm{b}} \chi^{2}$-Tests were used to test differences in characteristics between survivors with and without pre-disaster chronic diseases.

${ }^{c}$ Migraine, arthrosis, hypertension, asthma, COPD, liver disease, cancer, arthritis, diabetes, severe digestive disorder, heart disease, psoriasis, allergy, anaemia, severe disorder nervous system, thyroid gland disorder, severe visual or hearing problems, severe and long-lasting neck, back or shoulder symptoms/ diseases.

$* * p<0.0001, * p<0.05$ 
measured at all three waves and were examined in the present study: social functioning, general health perceptions, bodily pain, physical and emotional role limitations. At the three waves Cronbach's alpha was $>0.75$ for the five subscales.

Post-disaster feelings of depression and anxiety were measured by the Dutch version of the Symptom Checklist (SCL-90) [20]. The Cronbach's alpha at the three waves was $>0.93$ for both subscales. Intrusion and avoidance reactions, which are symptoms characteristic for PTSD, were assessed by the Dutch version of the Impact of Event Scale (IES) (Cronbach's alpha at the three waves $>0.83)$ [21-23].

\section{Statistical analyses}

Because the survey data were collected longitudinally, random coefficient analysis (RCA) was used (SAS version 9.1, MIXED procedure). This method allows for simultaneous analysis of variables that remain constant over time (e.g. gender) and time-varying variables (e.g. health problems), and takes into account the correlation of repeated measurements within subjects. In RCA, regression coefficients are allowed to vary between subjects. In the current analyses, random intercept models were used [24]. We controlled for gender, age, educational level, marital status, immigrant status and cigarette smoking. We did not control for disaster-related factors, because they were not different between survivors with and without predisaster chronic diseases.

\section{Results}

Chronic diseases were common in the study population; 427 survivors (35.1\%) had been diagnosed with one or more chronic diseases, of which high blood pressure $(\mathrm{N}=89)$, allergies $(\mathrm{N}=78)$ and arthrosis $(\mathrm{N}=54)$ were most common. Survivors with a pre-disaster chronic disease were more likely to be female, older, and of lower educational level, were more likely to be married and less likely to smoke cigarettes (Table 1).

Table 2 shows the results of the RCA with predisaster chronic disease as the predictor variable and the RAND-36 subscales and mental health scales as the dependent variables. There were significant chronic disease interaction effects only for social functioning, bodily pain and emotional role limitations at T2, but not at T3. For example, survivors with a chronic disease had smaller recovery of their social functioning at $\mathrm{T} 2(\beta=$ $-4.1 ; 95 \%$ CI $-7.9,-2.3)$ than survivors without a chronic disease. The course of post-disaster mental health problems did not differ between survivors with and without pre-disaster chronic diseases (Table 2).

\section{Discussion}

The results of the present study indicate that the course of post-disaster functional impairment and mental health symptoms was not consistently different for survivors with a chronic disease than for survivors without a chronic disease. Chronically ill survivors seemed to have somewhat more problems with social functioning and bodily pain, but fewer emotional role limitations 18 months postdisaster. We did, however, not find significant interaction effects for general health, physical role limitations, feelings of depression and anxiety and PTSD symptoms.

The results of some previous studies after disasters suggested an association between chronic disease and post-disaster health problems [25-27]. However, these studies had some limitations. First, the studies had only one post-disaster measurement and could not consider whether chronically ill survivors had a different course of post-disaster problems. In addition, the number of health outcomes examined in the studies were limited.

To our knowledge, this is the first study in which the association between pre-disaster chronic disease and post-disaster HRQL and mental health problems was the primary research question. Despite this, some potential limitations of the study deserve attention. First, although the mental health measures in this study are often used as screening instruments for mental disorders, we cannot rule out that assessments by diagnostic interviews might have resulted in different findings. In addition, since four domains of the RAND-36 were not measured at $\mathrm{T} 1$, we cannot exclude a different course for chronically ill survivors on these sub-scales. Secondly, only $30 \%$ of the total affected group participated at T1. After the 


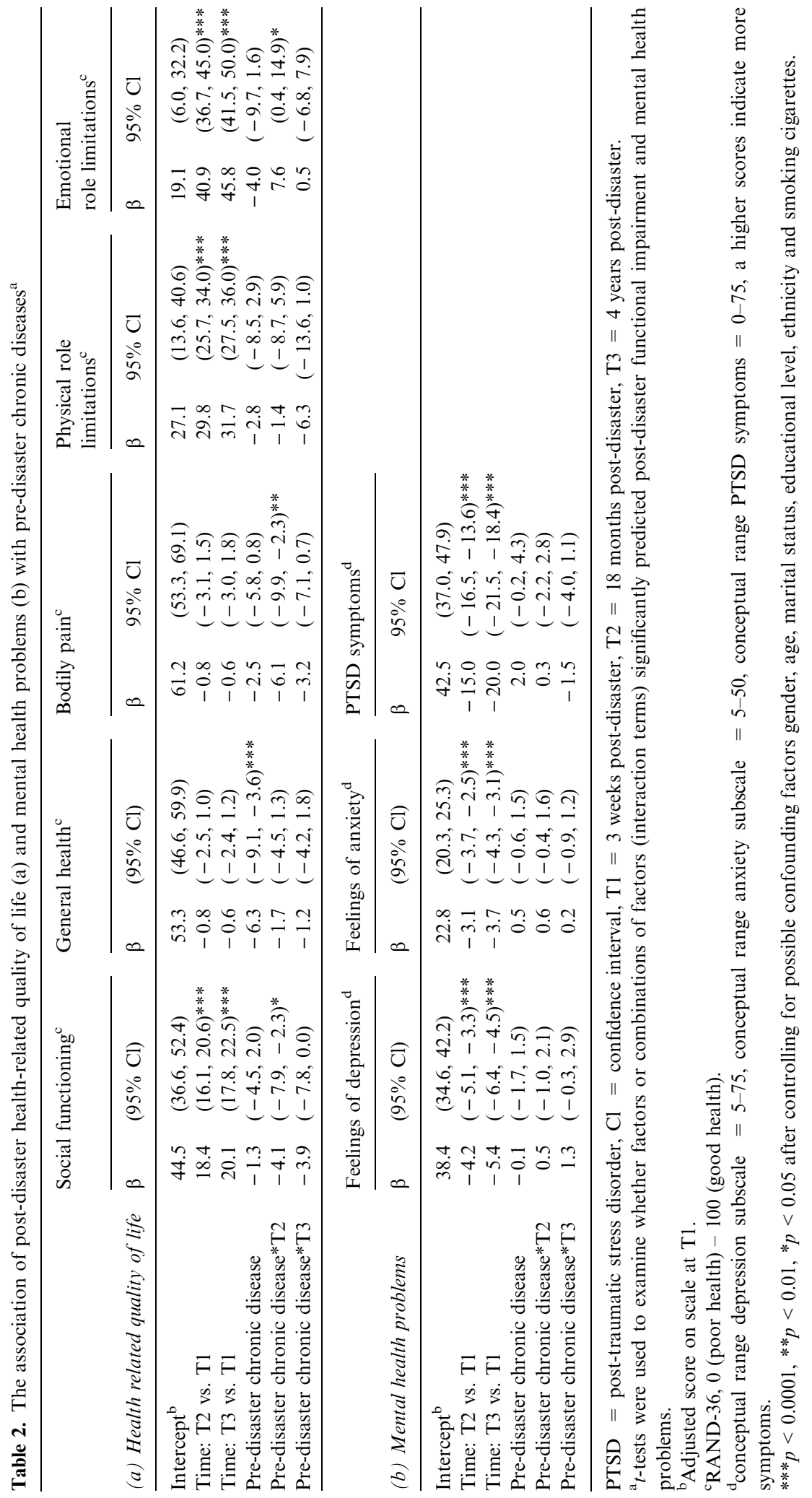


disaster, all survivors were registered at an information and advice center. Using this database, non-response analysis showed that fewer men, fewer younger (18-24 years) and fewer older survivors ( $\geq 65$ years), but relatively more immigrants participated in T1. However, multiple imputations, used to study potential selection bias, showed that the prevalence estimates of postdisaster health problems at $\mathrm{T} 1$ were most likely unaffected by non-response [28]. Also, despite some attrition at T2 and T3 it is unlikely that the association between chronic disease and postdisaster health problems was different among respondents than among dropouts. Thirdly, we can not rule out that differential post-disaster (medical) interventions or support for chronically ill survivors have occurred and confounded our findings. Finally, because of small numbers of survivors with each chronic disease, all chronically ill survivors were taken together in the analyses. It can be argued that the chronic diseases in our cluster have different characteristics, such as the degree of life threat, pain, and impairment. Therefore, we repeated the analyses with different clusters of chronic diseases, for example diseases that are predominately characterised by pain (e.g. severe neck, back or shoulder symptoms) or by impairment (e.g. diabetes and multiple scleroses). These analyses did not change the results (data not shown). This finding is supported by a study by Heijmans et al. in which various chronic diseases had many general stressors in common [29]. We also examined whether the results were different for survivors diagnosed with two or more chronic diseases compared to survivors with only one diagnosis. These analyses did not give different results (data not shown).

In conclusion, the results did not consistently indicate a different course of post-disaster health problems among the chronically ill. Therefore, we conclude that chronic disease is not an important risk factor for additional post-disaster functional impairment and mental health problems.

\section{Acknowledgements}

This longitudinal study was part of the Enschede Firework Disaster Health Monitoring Project (GGVE) and was performed under the authority of the Ministry of Health, Welfare and Sport in the Netherlands. Several research institutes cooperated on this study: The National Institute for Public Health and the Environment (RIVM), The Institute for Psychotrauma (IvP), the Netherlands Institute for Health Services Research (NIVEL), and the Department of Youth Health Care of the Regional Health Authority (GGD Regio Twente). The authors gratefully acknowledge the help of Petra ten Veen with the management of the GP dataset.

\section{References}

1. Alonso J, Ferrer M, Gandek B, et al. Health-related quality of life associated with chronic conditions in eight countries: Results from the International Quality of Life Assessment (IQOLA). Qual Life Res 2004; 13: 283-298.

2. Schlenk EA, Erlen JA, Dunbar-Jacob J, et al. Healthrelated quality of life in chronic disorders: A comparison across studies using the MOS SF-36. Qual Life Res 1998; 7: 57-65.

3. Stewart AL, Greenfield S, Hays RD, et al. Functional status and well-being of patients with chronic conditions. JAMA 1989; 262: 907-913.

4. Verhaak PFM, Heijmans MJWM, Peters L, et al. Chronic disease and mental disorder. Soc Sci Med 2005; 60: 789 797.

5. Polsky D, Doshi JA, Marcus S, et al. Long-term risk for depressive symptoms after a medical diagnosis. Arch Intern Med 2005; 165: 1260-1266.

6. Kessler RC, Ormel J, Demler O, et al. Comorbid mental disorders account for the role impairment of commonly occurring chronic physical disorders: results from the National Comorbidity Survey. JOEM 2003; 45: 1257-1266.

7. Sherbourne CD, Meredith LS, Rogers W, et al. Social support and stressful life events: Age differences in their effects on health-related quality of life among the chronically ill. Qual Life Res 1992; 1: 235-243.

8. Lin MR, Huan W, Huan C, et al. The impact of the ChiChi earthquake on quality of life among elderly survivors in Taiwan - a before and after study. Qual Life Res 2002; 11: 379-388.

9. Norris FH, Friedman MJ, Watson PJ, et al. 60,000 disaster victims speak: Part I. An empirical review of the empirical literature. Psychiatry 2002; 65: 207-239.

10. Yzermans CJ, Donker GA, Kerssens JJ, et al. Health problems of victims before and after disaster: A longitudinal study in general practice. Int J Epidemiol 2005; 34: 820826.

11. Galea S, Nandi A, Vlahov D. The epidemiology of posttraumatic stress disorder after disasters. Epidemiol Rev 2005; 27: 78-91.

12. Roorda J, Van Stiphout WA, Huijsman-Rubingh RRR. Post-disaster health effects: Strategies for investigation and data collection. Experiences from the Enschede firework disaster. J Epidemiol Commun Health 2004; 58: 982-987. 
13. Van Kamp I, Van der Velden PG, Stellato RK, et al. Physical and mental health shortly after a disaster: first results from the Enschede firework disaster study. Eur J Public Health 2006; 16: 252-258.

14. Dijkema MBA, Grievink L, Stellato RK, et al. Determinants of response in a longitudinal health study following the firework-disaster in Enschede, the Netherlands. Eur $\mathbf{J}$ Epidemiol 2005; 20: 839-847.

15. Grievink L, Van der Velden PG, Christiaanse B, et al. Fireworks Disaster Enschede: Health of Survivors Four Years after the Disaster [in Dutch]. Bilthoven/Zaltbommel, the Netherlands: National Institute for Public Health and the Environment/ Institute for Psychotrauma, 2004: 1-B52.

16. Stellato RK, Grievink L, Lebret E. Effects of dropout and item nonresponse in the follow-up of the victims of the Enschede firework disaster [abstract]. Epidemiology 2003; 14: S108.

17. Lamberts $\mathrm{H}$, Wood $\mathrm{M}$. International Classification of Primary Care. Oxford: Oxford University Press, 1987.

18. Van den Berg J, Van der Wulp CG. Rapport van de Werkgroep Revisie POLS-gezondheidsenquête 1999. Voorburg/ Heerlen: CBS, 2003.

19. Van der Zee KI, Sanderman R. Measuring General Health with the RAND-36: A Manual [in Dutch]. Groningen: Noordelijk Centrum voor Gezondheidsvraagstukken, 1993.

20. Arrindell WA, Ettema JHM. SCL-90: Manual for a Multidimensional Psychopathology Indicator [in Dutch]. Lisse: Swets \& Zeitlinger, 1986.

21. Horowitz MJ. Stress Response Syndromes. Oxford: Jason Aronson, 1976.
22. Brom D, Kleber RJ. De Schok Verwerkingslijst [The Dutch version of the impact of event scale]. Ned Tijdschr Psychologie 1985; 40: 164-168.

23. Van der Ploeg E, Mooren T, Kleber RJ, et al. Construct validation of the Dutch version of the impact of event scale. Psychol Assess 2004; 16: 16-26.

24. Singer JD, Willett JB. Applied Longitudinal Data Analysis. Modeling Change and Event Occurrence. New York: Oxford University Press, 2003.

25. Shore JH, Tatum EL, Vollmer WM. Evaluations of mental health effects of disaster, Mount St. Helens eruption. AJPH 1986; 76: 76-83.

26. Silver RC, Holman EA, McIntosh DN, Poulin M, GilRivas V. Nationwide longitudinal study of psychological responses to September 11. JAMA 2002; 288: 1235-1244.

27. Gignac MAM, Cott CA, Badley EM. Living with a chronic disabling illness and then some: Data from the 1998 ice storm. Can J on Aging 2003; 22: 249-259.

28. Grievink L, Van der Velden PG, Yzermans J, et al. The importance of estimating selection bias on prevalence estimates shortly after a disaster. Ann Epidemiol (in press).

29. Heijmans M, Rijken M, Foets M, et al. The stress of being chronically ill: From disease-specific to task-specific aspects. J Behav Med 2004; 27: 255-271.

Address for correspondence: Bellis van den Berg, National Institute for Public Health and the Environment (RIVM), P.O. Box 1, Postbak 10, 3720 BA, Bilthoven, The Netherlands Phone: + 313027425 52; Fax: +31 302744407

Email: bellis.van.den.berg@rivm.nl 